\title{
The Influence on Daylight and Energy Consumption of Expanded Metal Mesh Applied on Building Façades
}

\author{
$T S A Y$, Yaw-Shyan ${ }^{1, *}$, and $Y A N G$, Chih-Hung ${ }^{1}$ \\ ${ }^{1}$ Department of Architecture, National Cheng Kung University, Tainan, Taiwan
}

\begin{abstract}
Expanded metal mesh has become widely used as a shading element in the façade of many buildings in recent years, and its energy saving performance has been evaluated in tropical/subtropical countries. However, expanded metal mesh reduces solar radiation while also reducing the natural daylight entering the building. This study's objective is to assess the impact of expanded metal mesh on building energy consumption and natural daylighting.

The daylight effects on visual comfort and energy consumption of an office building located in Tainan, Taiwan were studied via building simulation program DIVA. Parameters including window to wall ratios (WWR), perforation rate expanded metal mesh, and glazing of window glass were studied, and a daylight standard of LEED rating system was used for evaluation.

The results showed that when the office building with large WWR and less glazing, the expanded metal mesh performed a better energy saving effect. For an office building with $50 \%$ WWR, the laminated clear glass and expanded metal mesh with $21 \%$ perforation rate were suggested to be the best design solution for meeting the LEED daylight standard and the lowest energy consumption.
\end{abstract}

Keywords: Building Simulation, DIVA, LEED

\section{Introduction}

In recent years, expanded metal mesh has become widely adopted as a shading element in the façade of many buildings, and its energy saving ability has been evaluated in the building codes of countries like Singapore and Taiwan, which are located in tropical and subtropical regions. Expanded metal mesh is sheet metal that has been cut and stretched to form a regular pattern of metal meshlike material. The 3D shape of the mesh reflects certain angles of solar radiation, while allowing some angles of solar radiation to pass through. These dual characteristics can promote the design flexibility of metal mesh on the façade and filter environmental elements that are not required.

However, since the shading device blocks solar radiation, it thus also reduces the daylighting in the building, so artificial lighting is required to achieve comfortable illumination, thus resulting in more energy consumption. Therefore, whether the shading device can effectively reduce the total energy consumption of a building is worthy of discussion.

Lin et al. [1] studied expanded metal mesh with different perforation rates and found that the practical transmittance was lower than the perforation rate, which meant that a higher shading performance could be evaluated. Alghoul et al. [2] demonstrated that the window-to-wall ratio and window orientation affect HVAC loading, and energy consumption increases with the window-to-wall ratio. Lau et al. (2016) showed that the energy consumption of office buildings is related to the external shading device and glazing type [3]. Meanwhile, Chi et al. (2017) studied different perforation rates, hole shapes, and hole distributions of perforated metal sheets. Their results revealed that the perforation rate is the main factor associated with daylight and energy consumption, and they found that using perforated metal mesh can increase the ratio of useful daylight illuminance (UDI) and reduce the solar radiation coming into buildings [4].

According to the above research, many factors will affect the energy consumption and daylighting of buildings, including window-to-wall ratio, shading device, and glazing type, but few studies have been carried out simultaneously with expanded metal mesh. This study aims to assess the impact of expanded metal mesh and architectural design factors on building energy consumption and natural daylighting.

\section{Methods}

\footnotetext{
* Corresponding author: tsayys@mail.ncku.edu.tw
} 


\subsection{Case study subject}

To evaluates the effects of different window-to-wall ratios (WWR), expanded metal mesh with different perforation rates, and different glazing types on building energy consumption and natural daylighting, we chose to simulate a typical medium-sized office building with a 40 m x 40 m 10-story RC structure (see Fig. 1).

We examined WWR at $30 \%, 50 \%$, and $80 \%$ and the following three kinds of glazing: laminated clear glass, laminated blue glass, and Low-E glass (see Table 1). The transmittance scenarios of expanded metal mesh are shown in Table 1. Since expanded metal mesh has a 3D structure, its practical transmittance differs from its perforation rate. In this study, the simulated transmittance in direct irradiation is the actual ratio of ambient and indoor solar radiation achieved by experiment, and it is equal to the perforation rate in indirect time. Furthermore, expanded metal mesh is only installed outside the windows of the east and west sides of the office building.

\subsection{Boundaries of simulation}

In this study, we adopted DIVA for Rhino to simulate lighting and energy consumption throughout the year. DIVA for Rhino is an optimized daylighting and energy model plug-in for the Rhino modeler, which enabled us to carry out a series of environmental performance evaluations, including annual and individual time step glare analysis, LEED and CHPS daylighting compliance, and energy calculations. The lighting simulation was based on Radiance and Daysim, while the energy calculation was based on EnergyPlus.

With regard to the simulation process, lighting simulation was first performed with DIVA to establish the lighting schedule (see Fig. 2), which was then imported into the DIVA-Archsim energy consumption simulator. In the simulation setting, the occupation time was from 8:00 to 18:00 on weekdays. The lighting switch was set with a Dimming with Occupancy On Off sensor option in the software lighting control system. After occupants left work, the lighting would not be switched on. In contrast, during office hours, the daylight harvesting system was used to offset the amount of electric lighting needed to properly light a space in order to reduce energy consumption. To accomplish this, a lighting control system that could dim or switch electric lighting in response to changing daylight availability was adopted. We set the standard target illuminance value required by office work as $500 \mathrm{~lx}$ at a height of $76 \mathrm{~cm}$.

In the energy simulation setting, the main structure of the office building case was set as the reinforced concrete structure commonly found in Taiwan. Moreover, we determined the indoor heat load related setting according to the recommendations of Taiwan's Green Building Regulations, thus setting occupant density to 0.15 person $/ \mathrm{m}^{2}$, equipment density to $13.5 \mathrm{~W} / \mathrm{m}^{2}$, air conditioning temperature set-point to $26^{\circ} \mathrm{C}$, and outdoor air flow rate to $8.5 \mathrm{~L} /(\mathrm{s} \cdot$ person).

\subsection{Evaluation standard of simulation results}

In this study, we used the daylight standard of Leadership in Energy and Environmental Design (LEED) for evaluation. Spatial Daylight Autonomy (sDA) and Annual Sunlight Exposure (ASE) were adopted as two important measures for better understanding annual daylight availability and quality, as well as glare potential.

sDA was defined as the area in which illumination of the working plane reached $300 \mathrm{~lx}$ over $50 \%$ of the working time, and ASE was defined as the area in which illumination of the working plane reached over $1000 \mathrm{~lx}$ for more than 250 hours. Regarding office specifications, when the sDA value was $55 \%-74 \%$ and the ASE value was less than $10 \%, 2$ points were given; when the sDA value was $75 \%$ or more, and the ASE value was less than $10 \%, 3$ points were given.

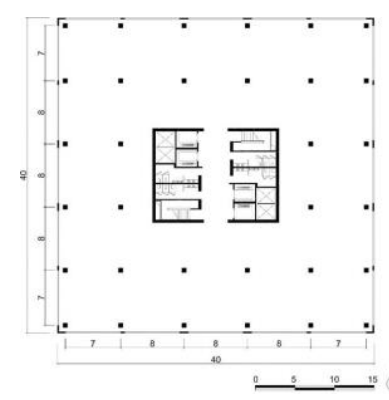

(a)

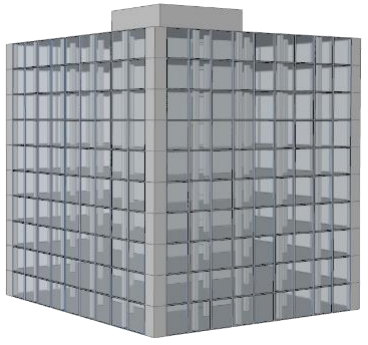

(b)
Fig. 1. (a) Standard floor plan configuration (b) Simulation model $(\mathrm{WWR}=80 \%)$

Table 1. Glazing properties of three kinds of glass.

\begin{tabular}{|c|c|c|c|c|}
\hline \multirow{2}{*}{ Glass type } & Thickness & $\begin{array}{c}\text { Visible } \\
\text { transmittance }\end{array}$ & SHGC & U-value \\
\cline { 2 - 5 } & $\mathrm{m}$ & - & - & $\mathrm{W} / \mathrm{m}^{2} \mathrm{~K}$ \\
\hline $\begin{array}{c}\text { Laminated } \\
\text { clear glass }\end{array}$ & 0.012 & 0.87 & 0.73 & 4.88 \\
\hline $\begin{array}{c}\text { Laminated } \\
\text { blue glass }\end{array}$ & 0.012 & 0.60 & 0.53 & 4.88 \\
\hline $\begin{array}{c}\text { Low-E } \\
\text { glass }\end{array}$ & 0.012 & 0.53 & 0.26 & 1.64 \\
\hline
\end{tabular}

Table 2. Solar radiation transmittance of three kinds of expanded metal mesh.

\begin{tabular}{|c|c|c|c|c|c|}
\hline \multirow{2}{*}{$\begin{array}{c}\text { Expanded } \\
\text { metal }\end{array}$} & \multirow{2}{*}{$\begin{array}{c}\text { Perforation } \\
\text { mesh }\end{array}$} & Rate (\%) & \multicolumn{3}{|c|}{ Practical transmittance (\%) } \\
\cline { 3 - 6 } type & & $8: 00$ & $12: 00$ & $8: 00$ & $12: 00$ \\
& & I & I & I & I \\
& & $12: 00$ & $18: 00$ & $12: 00$ & $18: 00$ \\
\hline A & 81 & 52 & 81 & 81 & 52 \\
\hline B & 42 & 31 & 42 & 42 & 31 \\
\hline C & 21 & 13 & 21 & 21 & 13 \\
\hline
\end{tabular}




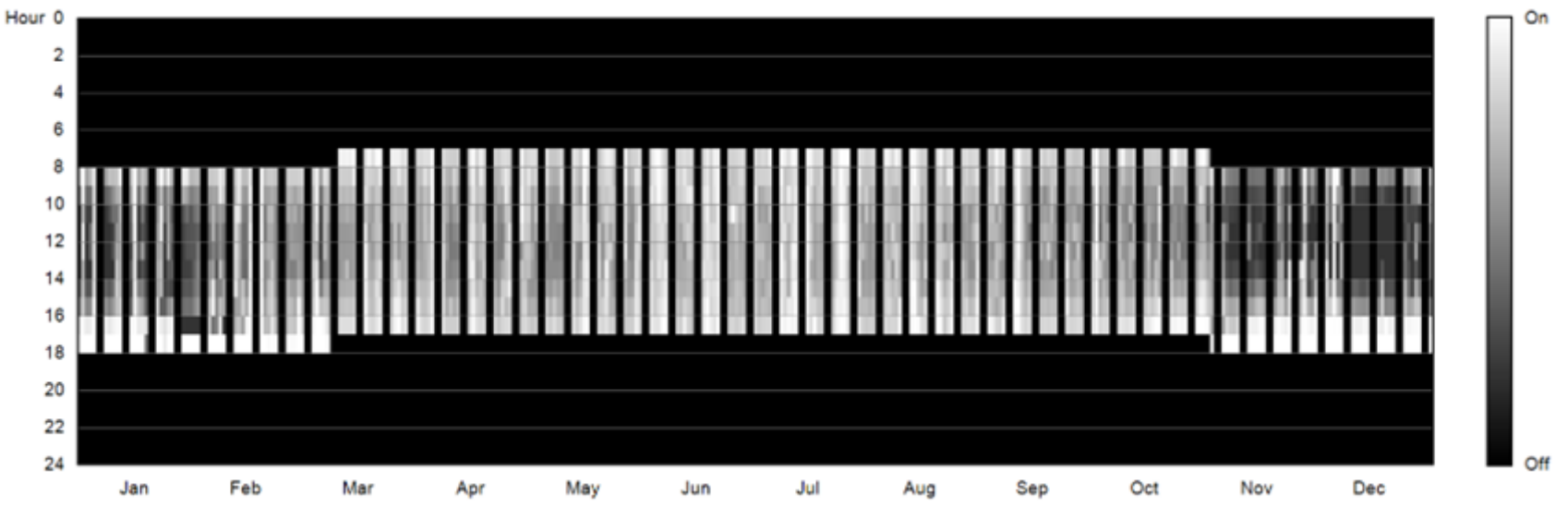

Fig. 2. The lighting schedule output by DIVA. (Scenario 28 : WWR $=30 \%$, Perforation rate $=21 \%$, Laminated clear glass)

Table 3. The daylighting and energy consumption simulation results of 36 scenarios.

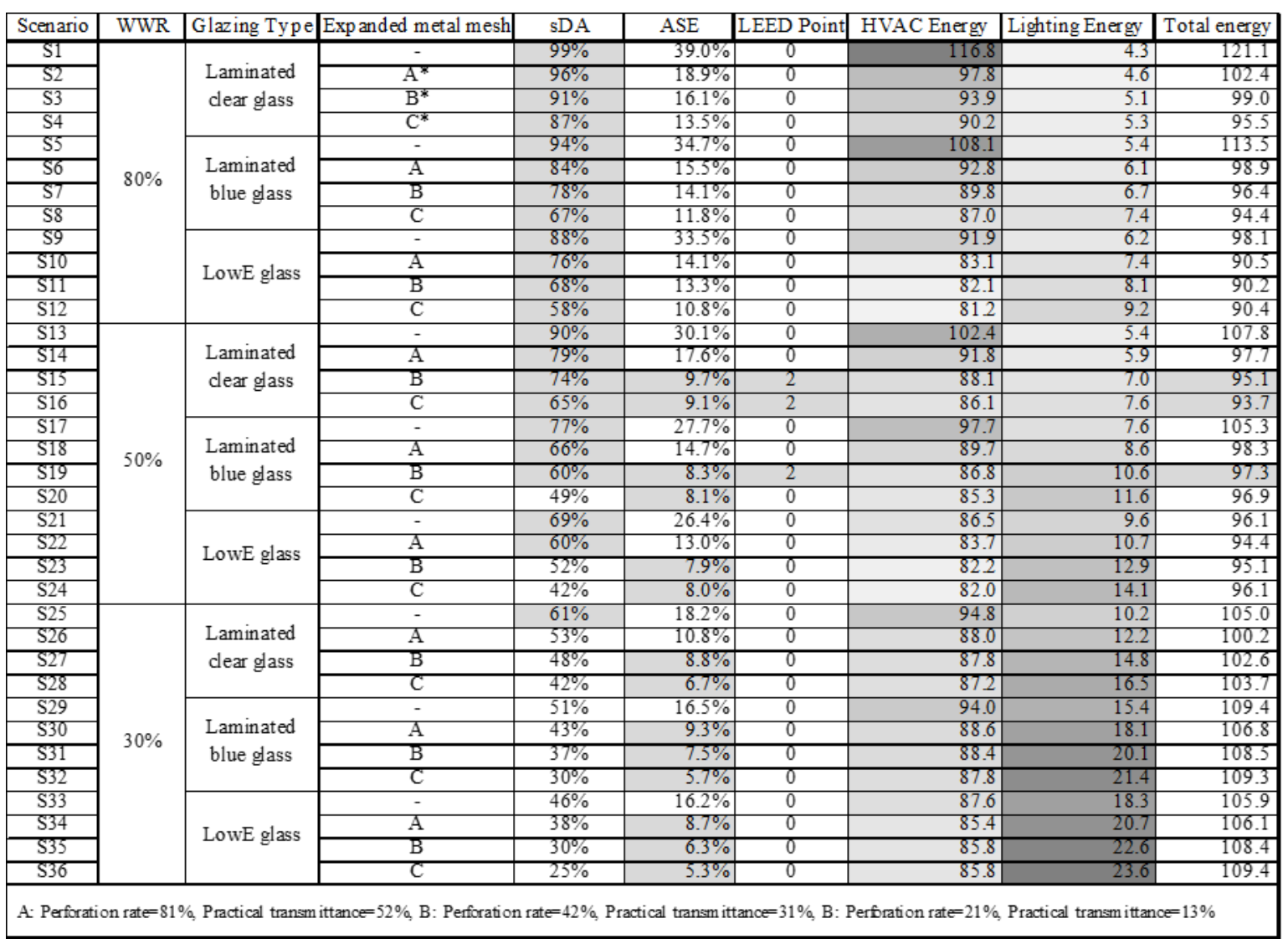

\section{Results and discussion}

In this study, 36 simulation scenarios were performed according to different WWR, glass properties, and perforation rates of expanded metal mesh. The lighting simulation results were evaluated according to the LEED lighting requirement. With regard to energy consumption, this study evaluated the performance of lighting and air conditioning energy consumption.

The summarized results are shown in Table 3. Nine scenarios without expanded metal mesh did not reach the daylighting standard, primarily because their illuminations exceeded the ASE standard. However, after expanded metal mesh was installed at the openings of the building, the ASE value was significantly reduced.

Our results showed that the expanded metal mesh effectively reduced direct and excessive sunlight. Nevertheless, if a Low-E glass with a low visible transmittance was used, the influence of the expanded metal mesh on preventing excessive light was also lowered. As shown in Table 4, in 36 scenarios, only S15, S16, and S19 conform with the LEED daylight standard. As shown in Figures 3, 4, and 5, the energy saving ratio of the scenario with $80 \%$ WWR was greater than the scenarios with $30 \%$ and $50 \%$ WWR. In other words, the greater the WWR, the greater the energy saving potential of expanded metal mesh and glazing. As for glazing type, the lower the SHGC value of the glass, the smaller the 
influence of the expanded metal mesh on HVAC energy saving.

In order to save air conditioning energy consumption, expanded metal mesh with a low perforation rate was used, which then increased lighting energy consumption due to insufficient illumination. In particular, when Low-E glass with a low solar heat gain coefficient was used, the expanded metal mesh resulted in a significant increase in lighting energy consumption. Taking S11 and S12 as examples, when the building was $80 \%$ WWR coupled with Low-E glass and expanded metal mesh with a $21 \%$ perforation rate, the energy consumption of the air conditioning could compare to the $42 \%$ perforation rate expanded metal mesh to reduce 1 EUI, but the lighting energy was increased 1.1 EUI. Overall, using $\mathrm{C}$ mesh consumed more energy than the B mesh.

\section{Conclusions}

In this study, we adopted three factors commonly applied to building facade design to discuss the impact of lighting and air conditioning energy consumption. According to the results of our lighting simulations, only three scenarios conformed with the LEED daylight standard, and S16, which consisted of 50\% WWR, laminated clear glass, and expanded metal mesh with a $21 \%$ perforation rate, displayed the greatest energy efficiency.

We also found WWR to be the main factor influencing the amount of daylight entering the building. Therefore, the greater the WWR, the greater the energy saving potential expanded metal mesh and glazing have.

With regard to the building energy consumption simulation, the lighting schedules output from DIVA with the daylight harvesting systems were input to the energy consumption simulation, enabling us to discuss the energy saving effect of daylight. The results demonstrated that the expanded metal mesh could effectively reduce direct and excessive sunlight. Nevertheless, if a Low-E glass with low visible transmittance is used, the influence of the expanded metal mesh on preventing excessive light would be reduced. When WWR is $80 \%$ and $50 \%$, glazing with a higher visible transmittance can be used with expanded metal mesh to achieve better energy saving and daylighting quality. However, when the WWR was $30 \%$, scenarios in which Low-E glass and expanded metal mesh were used at the same time are not recommended.

Table 4. Results of the three scenarios that reached the daylight standard

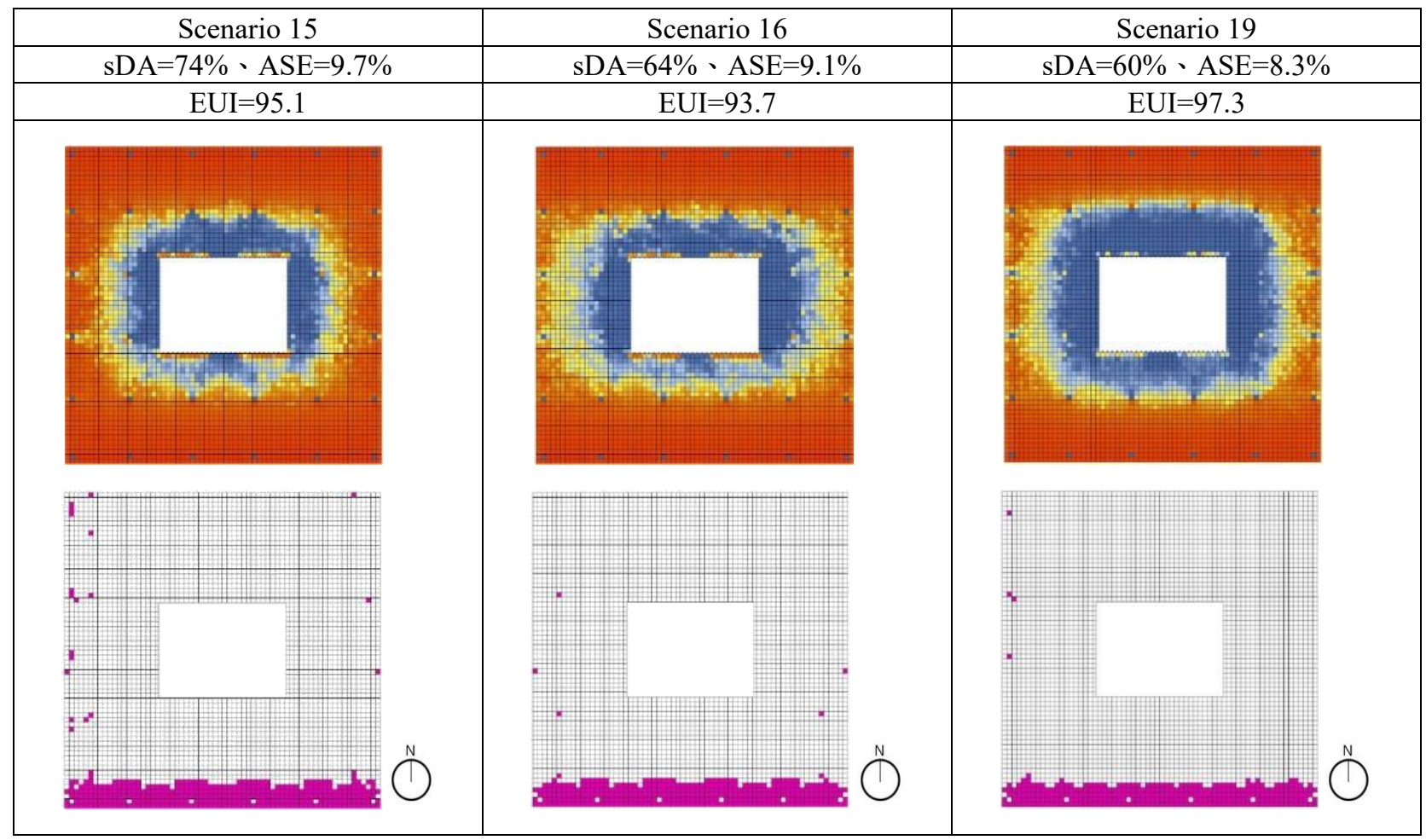




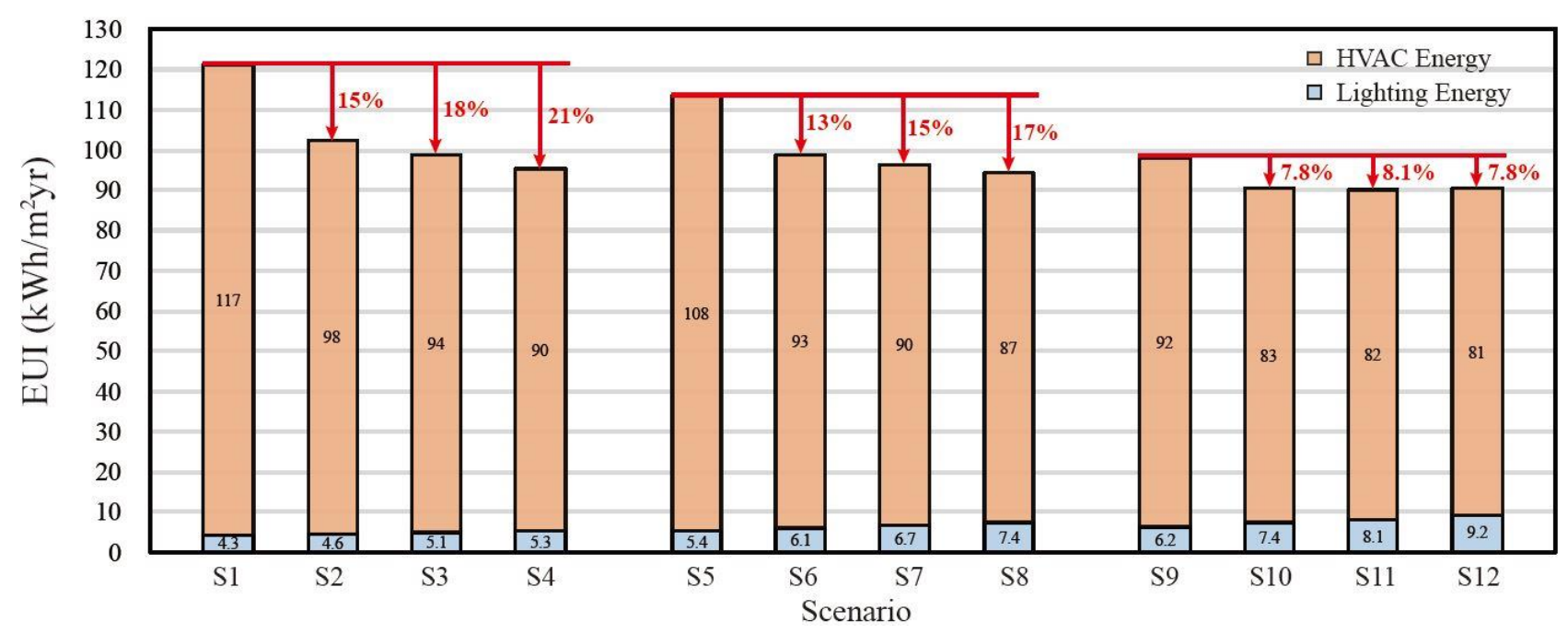

Fig. 3. Energy consumption throughout the whole year, $\mathrm{WWR}=80 \%$.

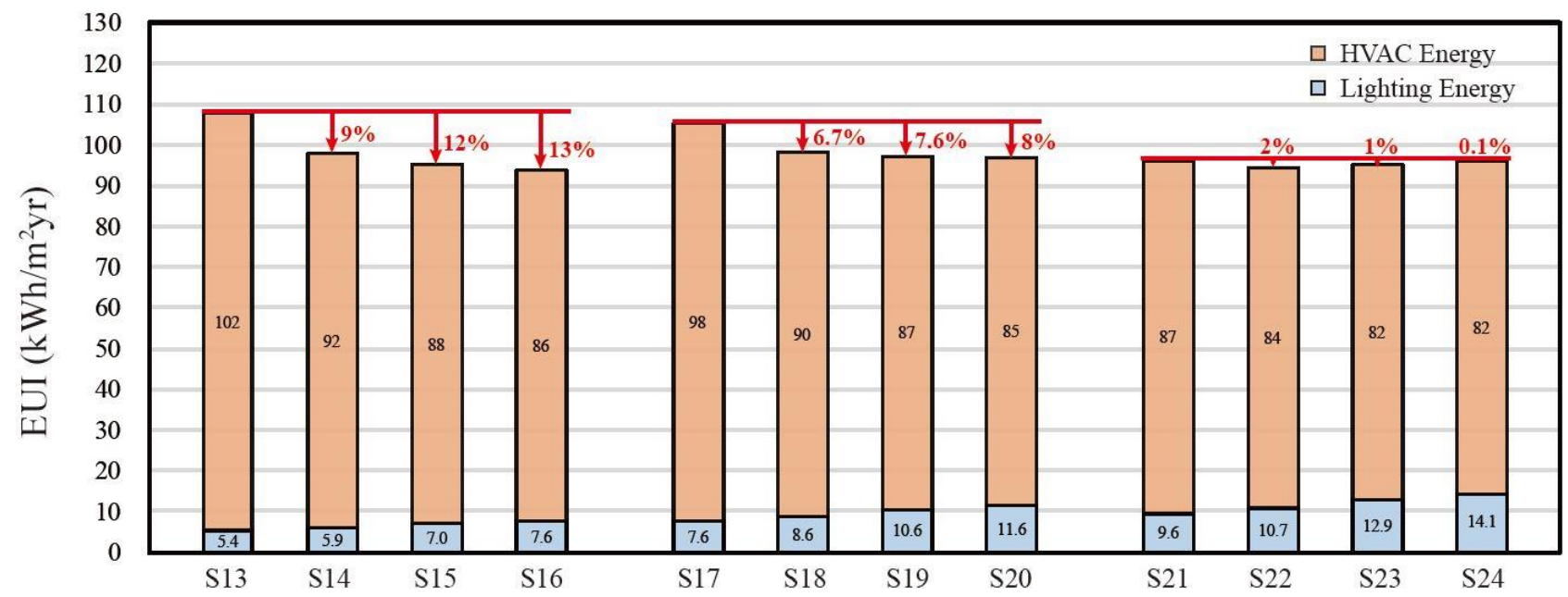

Fig. 4. Energy consumption throughout the whole year, $\mathrm{WWR}=50 \%$.

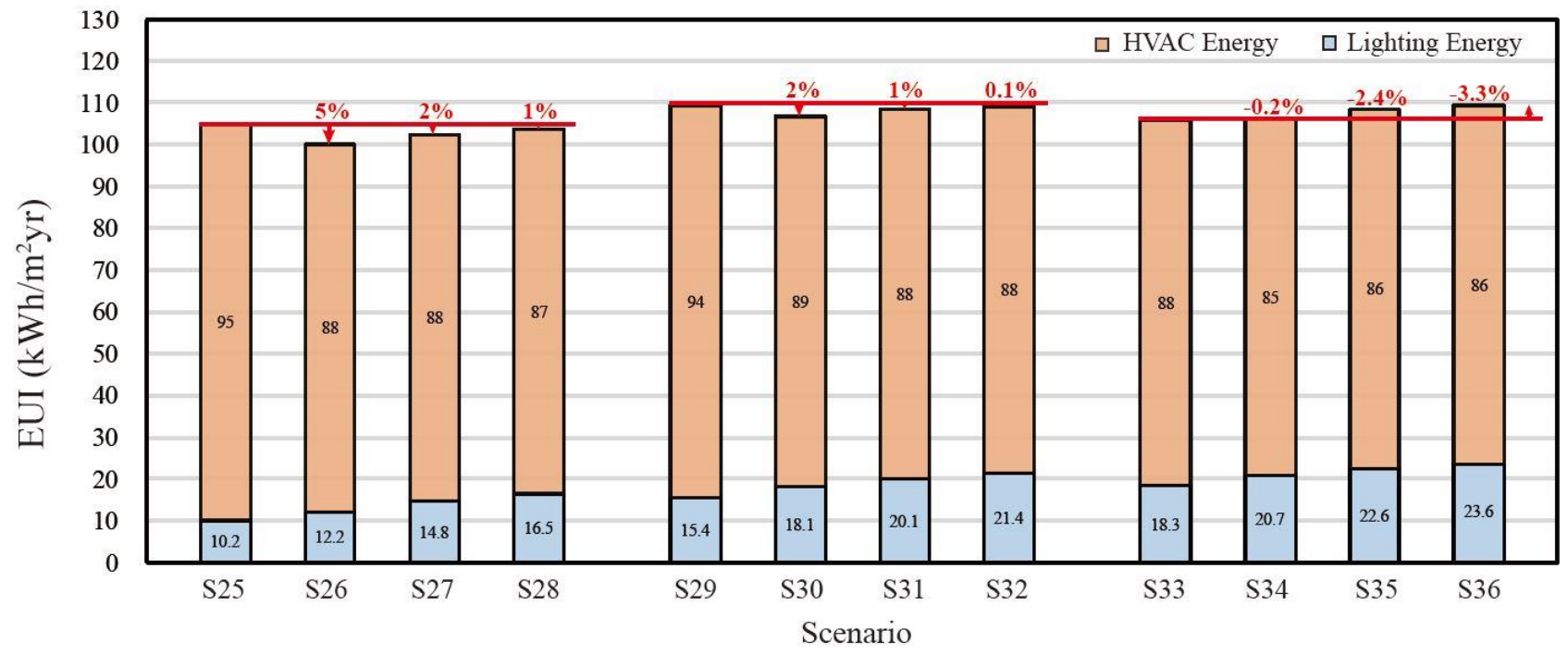

Fig. 5. Energy consumption throughout the whole year, $\mathrm{WWR}=30 \%$. 


\section{References}

1. C.H. Lin, Y.S. Tsay, J.H. Yang, Y.F. Lin, World Sustainable Built Environment Conference, (2017)

2. S.K. Alghoul, H.G. Rijabo, M.E. Mashena. Building Engineering, 11, 82-86, (2017).

3. D.A. Chi, D. Moreno, J. Navarro. Build. Environ., 125, 383-400, (2017).

4. A.K.K. Lau, E. Salleh, C.H. Lim, M.Y. Sulaiman, International Journal of Sustainable Built Environment, 5, 387-399, (2016). 